\title{
Efikasi Dry Ice terhadap Sitophilus oryzae dan Tribolium castaneum pada Beras Kemasan Plastik di Dataran Tinggi
}

\section{Efficacy of Dry Ice to Sitophilus oryzae and Tribolium castaneum in The Rice of Plastic Packaging at High Land}

\author{
Aisyah $^{1)}$, Subagiya ${ }^{2)}$, Ato Sulistyo $^{2)}$
}

\begin{abstract}
Sitophilus oryzae and Tribolium castaneum are pest that can always attack rice in long periode storage. Rice in the plastic packaging that spread in market has not did fumigation, so the pest can attack faster than rice in sack packaging. This research was aimed to understand the effectiveness of dry ice to attack $S$. oryzae and $T$. castaneum with effect of dry ice to rice in plastic packaging at high land. This research used completely randomized design (CRD) with two factors. The first factor was dose of dry ice and second factor was wrapper of dry ice. The data was analyzed in variance analysis then continue with Duncan Mean Range Test (DMRT). The result showed that dose of dry ice $10 \mathrm{~g} /$ rice $5 \mathrm{~kg}$ can effect for $90,83 \%$ mortality of $S$. oryzae and $T$. castaneum but it have not made effect for imago and larvae population. Also, dry ice was not make effect for rice weight and rice quality (color of rice, scent of rice and taste of rice).
\end{abstract}

Keywords : dry ice, Sitophilus oryzae L., Tribolium castaneum Herbst., fumigation, rice

\section{PENDAHULUAN}

Proses pemasaran dan penyimpanan beras yang cukup lama dalam gudang memiliki resiko terserang hama pasca panen, bahkan pada beras kemasan plastik berukuran $5 \mathrm{~kg}$ yang sering dijual di pasaran maupun supermarket. Kemasan plastik beras ketika masih di pabrik kemungkinan masih bagus dan bersih, tetapi ketika sampai pada konsumen beberapa memiliki masalah adanya serangan hama beras. Menurut Sakul et al. (2012), serangga yang banyak merusak hasil pertanian khususnya beras terutama dari jenis kumbang Coleoptera yaitu Sitophilus oryzae L. dan Tribolium castaneum Herbst. Hal tersebut bisa terjadi karena tidak adanya perlakuan fumigasi sehingga telur-telur kumbang beras yang belum menetas akan mengganggu komoditas beras yang akan disimpan dalam jangka waktu lama.

Perlakuan fumigasi pada pabrik hanya bisa dilakukan pada beras kemasan karung karena pada kemasan plastik tidak adanya lubang udara untuk perlakuan fumigasi. Dry ice dapat dijadikan sebagai fumigasi alternatif pada beras kemasan plastik. Menurut Henie (2012) dry ice merupakan gas $\mathrm{CO}_{2}$ yang dipadatkan pada suhu $-79{ }^{\circ} \mathrm{C}$. Dry ice tersebut nantinya akan dibungkus rapi dan akan dimasukkan ke dalam beras kemasan plastik dalam dosis tertentu. Kerja dry ice nantinya akan membuat suasana dalam beras kemasan plastik menjadi anaerob sehingga hama di dalam beras tidak mampu bertahan hidup.

\footnotetext{
1) Undergraduate Student of Study Program of Agrotechnology, Faculty of Agriculture, Sebelas Maret University (UNS) in Surakarta

2) Lecturer Staff of Study Program of Agrotechnology, Faculty of Agriculture, Sebelas Maret University (UNS) in Surakarta
}

Contact Author: aisyahuns@gmail.com
Penelitian ini berguna untuk mengkaji dosis dry ice efektif yang dapat mengendalikan $S$. oryzae dan $T$. castaneum pada beras kemasan plastik ukuran $5 \mathrm{~kg}$ di daerah dataran tinggi. Berbagai jenis pembungkus dry ice juga digunakan untuk mengetahui pembungkus dry ice yang tepat untuk diterapkan sebagai pembungkus fumigan. Selain itu, penelitian ini juga menguji pengaruh dry ice terhadap kualitas beras seperti warna beras, bau beras dan rasa nasi.

\section{METODE PENELITIAN}

Penelitian ini telah dilaksanakan di Desa Kalisoro, Kelurahan Kalisoro, Kecamatan Tawangmangu, Karanganyar dan Lab Hama dan Penyakit Fakultas Pertanian UNS pada bulan Juli sampai Oktober 2014. Alat yang digunakan dalam penelitian ini meliputi timbangan analitik dengan skala 1 sampai $6 \mathrm{~kg}$, toples, alat pres plastik dan pembungkus dry ice (tisu keras, tea bag, kain keras). Bahan penelitian yang digunakan adalah beras $\mathrm{C} 4$, dry ice, S. oryzae dan $T$. castaneum.

Penelitian ini menggunakan Rancangan Acak Lengkap yang terdiri dari 9 perlakuan sebagai berikut:

$A=$ Perlakuan tanpa infestasi $S$. oryzae dan $T$. castaneum dan dry ice

$\mathrm{B}=$ Perlakuan dengan infestasi $S$. oryzae dan $T$. castaneum tanpa dry ice

$\mathrm{C}=$ Perlakuan dengan dosis dry ice $10 \mathrm{~g} /$ beras $5 \mathrm{~kg}$ tanpa infestasi $S$. oryzae dan $T$. castaneum

$\mathrm{D}=$ Perlakuan infestasi $S$. oryzae dan $T$. castaneum dengan dosis dry ice $8 \mathrm{~g} / \mathrm{beras} 5 \mathrm{~kg}$ dan pembungkus dry ice kain keras

$\mathrm{E}=$ Perlakuan infestasi $S$. oryzae dan $T$. castaneum dengan dosis dry ice $8 \mathrm{~g} / \mathrm{beras} 5 \mathrm{~kg}$ dan pembungkus dry ice tea bag

$\mathrm{F}=$ Perlakuan infestasi $S$. oryzae dan $T$. castaneum dengan dosis dry ice $8 \mathrm{~g} /$ beras $5 \mathrm{~kg}$ dan pembungkus dry ice tisu keras

Efikasi dry ice terhadap sitophilus oryzae dan tribolium castaneum pada beras kemasan plastik di dataran tinggi. Aisyah, Subagiya, Ato Sulistyo. 
$\mathrm{G}=$ Perlakuan infestasi $S$. oryzae dan $T$. castaneum dengan dosis dry ice $10 \mathrm{~g} / \mathrm{beras} 5 \mathrm{~kg}$ dan pembungkus dry ice kain keras

$\mathrm{H}=$ Perlakuan infestasi $S$. oryzae dan $T$. castaneum dengan dosis dry ice $10 \mathrm{~g} /$ beras $5 \mathrm{~kg}$ dan pembungkus dry ice tea bag

$\mathrm{I}=$ Perlakuan infestasi $S$. oryzae dan $T$. castaneum dengan dosis dry ice $10 \mathrm{~g} /$ beras $5 \mathrm{~kg}$ dan pembungkus dry ice tisu keras

(Masing-masing perlakuan tersebut diulang 3 kali).

Variabel penelitian yang diamati adalah mortalitas, jumlah populasi imago dan larva dari $S$. oryzae dan $T$. castaneum, serta pengaruh dry ice terhadap beras yang meliputi berat beras, warna beras, bau beras dan rasa nasi. Data yang diperoleh kemudian dianalisis menggunakan analisis ragam pada taraf 5 $\%$ serta dilanjutkan dengan Uji Jarak Berganda Duncan (DMRT).

\section{HASIL DAN PEMBAHASAN}

\section{Mortalitas Sitophilus oryzae dan Tribolium castaneum}

Mortalitas merupakan uji kematian hama setelah diberi perlakuan dry ice selama sebulan. Uji mortalitas merupakan variabel pengamatan utama dalam penelitian ini karena berguna untuk mengetahui seberapa efektif dry ice yang diberikan dalam mengendalikan $S$. oryzae dan $T$. castaneum. Hasil analisis data uji ragam menunjukkan bahwa mortalitas $S$. oryzae dan $T$. castaneum berbeda nyata antar perlakuan. Hasil analisis ragam mortalitas $S$. oryzae dan $T$. castaneum dapat dilihat pada tabel 1.

Berdasarkan tabel 1 terlihat bahwa mortalitas tertinggi adalah perlakuan dengan infestasi $S$. oryzae dan T. castaneum beserta pemberian dosis dry ice 10 $\mathrm{g} /$ beras $5 \mathrm{~kg}$ dengan pembungkus dry ice kain keras dan tisu keras sebesar 90,83 \%. Besar mortalitas perlakuan dengan dosis dry ice $8 \mathrm{~g} /$ beras $5 \mathrm{~kg}$ dan pembungkus dry ice kain keras, tea bag, tisu keras secara berturut-turut hanya 81,66 \%, $85 \%$, dan 84,16 $\%$. Hal tersebut tidak berbeda jauh dengan mortalitas perlakuan infestasi $S$. oryzae dan $T$. castaneum tanpa dry ice sebesar $72,5 \%$. Padahal perlakuan juga mendapatkan infestasi hama tanpa pengaruh dosis dry ice, tetapi nilai mortalitasnya termasuk tinggi. Hal tersebut bisa terjadi karena faktor usia hama yang sudah tidak produktif atau terlalu tua sehingga mudah mati.

Hasil mortalitas beberapa perlakuan tidak bisa 100 \% karena diduga selama penelitian, kemasan beras yang digunakan masih kurang rapat sehingga dosis dry ice yang diberikan belum mencapai hasil maksimal. Menurut Harpini (2013), perlakuan fumigasi harus dilaksanakan dalam ruangan kedap gas, harus tanpa lubang atau celah yang dapat mengakibatkan keluarnya fumigan dari ruang fumigasi. Syarat melakukan fumigasi $\mathrm{CO}_{2}$ adalah kondisi sasaran fumigasi harus terisi $\mathrm{CO}_{2}$ secara maksimal.

\section{Populasi Imago Sitophilus oryzae dan Tribolium castaneum}

Populasi imago menunjukkan jumlah imago hama yang masih bisa bertahan hidup di akhir pengamatan. Pada tabel 1 menunjukkan bahwa imago $S$. oryzae akhir yang masih hidup adalah perlakuan infestasi $S$. oryzae dan $T$. castaneum tanpa dry ice sebesar 3 ekor, perlakuan infestasi $S$. oryzae dan $T$. castaneum dengan dosis dry ice $8 \mathrm{~g} /$ beras $5 \mathrm{~kg}$ dan pembungkus dry ice tisu keras sebesar 1 ekor dan perlakuan infestasi $S$. oryzae dan $T$. castaneum dengan dosis dry ice $10 \mathrm{~g} /$ beras $5 \mathrm{~kg}$ dan pembungkus dry ice tea bag sebesar 2 ekor. Populasi $S$. oryzae tertinggi adalah perlakuan infestasi $S$. oryzae dan $T$. castaneum tanpa dry ice karena tidak adanya efek dry ice. Hal tersebut menunjukkan bahwa dry ice mampu mengendalikan imago $S$. oryzae sehingga kematian imago akhir lebih tinggi.

Berbeda halnya dengan pengaruh dry ice terhadap populasi imago akhir $T$. castaneum yang tidak berbeda nyata antar perlakuan. Pada tabel 1, perlakuan infestasi $S$. oryzae dan $T$. castaneum tanpa dry ice yaitu infestasi $S$. oryzae dan $T$. castaneum tanpa dry ice menunjukkan populasi imago $T$. castaneum paling besar yaitu 9 ekor, tetapi perlakuan lain juga sama besar. Artinya imago $T$. castaneum pada perlakuan yang berbeda setelah diberi dry ice tetap banyak yang bertahan hidup. Hal tersebut membuktikan bahwa dry ice tidak berpengaruh terhadap populasi imago T. castaneum.

Tabel 1. Tabel tabulasi silang mortalitas, populasi imago, populasi larva $S$. oryzae dan T. castaneum

\begin{tabular}{|c|c|c|c|c|}
\hline \multirow[b]{2}{*}{ Perlakuan } & \multicolumn{4}{|c|}{ Pengamatan } \\
\hline & $\begin{array}{l}\text { Mortalitas } \\
\text { S. oryzae dan } \\
\text { T. castaneum (\%) }\end{array}$ & $\begin{array}{l}\text { Populasi Imago } \\
\text { S. oryzae (ekor) }\end{array}$ & $\begin{array}{l}\text { Populasi Imago } \\
T \text {. castaneum } \\
\text { (ekor) }\end{array}$ & $\begin{array}{l}\text { Populasi Larva } \\
\text { T. castaneum (ekor) }\end{array}$ \\
\hline$A$ & $00,00 \mathrm{a}$ & $0 \mathrm{a}$ & $0 \mathrm{a}$ & $0 \mathrm{a}$ \\
\hline B & $72,50 \mathrm{~b}$ & $3 b$ & $9 \mathrm{~b}$ & $107 \mathrm{~b}$ \\
\hline C & $00,00 \mathrm{a}$ & $0 \mathrm{a}$ & $0 \mathrm{a}$ & $0 \mathrm{a}$ \\
\hline $\mathrm{D}$ & $81,66 \mathrm{bc}$ & $0 \mathrm{a}$ & $7 \mathrm{~b}$ & $34 a b$ \\
\hline$E$ & $85,00 \mathrm{bc}$ & $0 \mathrm{a}$ & $6 a b$ & $85 a b$ \\
\hline $\mathrm{F}$ & $84,16 \mathrm{bc}$ & $1 \mathrm{a}$ & $6 a b$ & $60 a b$ \\
\hline $\mathrm{G}$ & $90,83 \mathrm{c}$ & $0 \mathrm{a}$ & $4 a b$ & $40 a b$ \\
\hline $\mathrm{H}$ & $78,33 \mathrm{bc}$ & $2 a b$ & $4 a b$ & $64 a b$ \\
\hline 1 & $90,83 \mathrm{c}$ & $0 \mathrm{a}$ & $4 a b$ & $32 a b$ \\
\hline
\end{tabular}

Keterangan: Angka yang diikuti huruf yang sama pada kolom yang sama menunjukan tidak berbeda nyata pada Uji Jarak Berganda Duncan pada taraf 5\% 


\section{Populasi Larva Sitophilus oryzae dan Tribolium castaneum}

Populasi larva hama menunjukkan terjadinya natalitas pada hama yang masih bertahan hidup. Banyak larva hama yang ditemukan pada pengamatan akhir dan secara keseluruhan merupakan larva dari $T$. castaneum. Jumlah larva $S$. oryzae secara keseluruhan tidak ada yang artinya tidak terjadi natalitas pada $S$. oryzae.. Hasil perlakuan $S$. oryzae dan $T$. castaneum tanpa perlakuan dry ice menunjukkan populasi larva $T$. castaneum mencapai 107 ekor. Hal ini terjadi karena pada perlakuan tersebut tidak adanya efek dry ice yang dapat membunuh larva.

Larva $T$. castaneum berkembang sangat cepat terutama di daerah dataran tinggi yang memiliki kelembaban udara tinggi. Kelembaban udara 30\% meningkatkan mortalitas larva, sedangkan kelembaban $10 \%$ menyebabkan larva mati (Anggara dan Sumardji 2009). Perlakuan D. E, F, G, H dan I dengan pemberian dosis dry ice $8 \mathrm{~g} /$ beras $5 \mathrm{~kg}$ dan dosis dry ice $10 \mathrm{~g} /$ beras $5 \mathrm{~kg}$ dengan pembungkus $d r y$ ice berbeda juga memiliki populasi larva berturut-turut sebesar 34, 85, 60, 40, 64, 32 ekor. Jumlah larva demikian termasuk tinggi, sehingga kerja dry ice tidak berpengaruh pada populasi larva hama

\section{Berat Beras}

Berat beras diamati untuk mengetahui ada tidaknya perbedaan berat yang signifikan setelah beras diberi perlakuan dry ice. Hasil dari berat beras akhir dapat dilihat pada tabel 2 .

Tabel 2. Pengaruh dry ice terhadap berat beras selama lima minggu

\begin{tabular}{|c|c|c|}
\hline Dosis Dry Ice & Perlakuan & Berat Beras Akhir (g) \\
\hline & A & $5004,67 a$ \\
\hline 0 g/beras 5 kg & B & $4997,33 \mathrm{a}$ \\
\hline \multirow{3}{*}{$8 \mathrm{~g} /$ beras $5 \mathrm{~kg}$} & $\mathrm{D}$ & $5008,00 \mathrm{a}$ \\
\hline & $\mathrm{E}$ & $5006,00 \mathrm{a}$ \\
\hline & $\mathrm{F}$ & $5006,00 \mathrm{a}$ \\
\hline \multirow{4}{*}{$10 \mathrm{~g} /$ beras $5 \mathrm{~kg}$} & $\mathrm{C}$ & $5009,33 a$ \\
\hline & G & $5008,00 \mathrm{a}$ \\
\hline & $\mathrm{H}$ & $5000,33 a$ \\
\hline & I & $5008,67 \mathrm{a}$ \\
\hline
\end{tabular}

Keterangan: Angka yang diikuti huruf yang sama menunjukan tidak berbeda nyata pada Uji Jarak Berganda Duncan pada taraf $5 \%$

Pada tabel 2 menunjukkan bahwa berat beras rata-rata mengalami penambahan berat lebih dari 5000 gram kecuali perlakuan infestasi $S$. oryzae dan T. castaneum tanpa dry ice. Penambahan bisa terjadi karena mulai terjadinya pengaruh dry ice yang menyublim sehingga membuat $\mathrm{CO}_{2}$ yang memenuhi pembungkus plastik menimbulkan kelembaban yang bertambah sehingga berat beras bertambah. Perlakuan tanpa infestasi $S$. oryzae dan $T$. castaneum, dry ice juga mengalami penambahan berat beras akhir bisa disebabkan karena kelembaban selama di tempat penyimpanan di daerah dataran tinggi Tawangmangu maka kelembaban beras juga bertambah. Perlakuan infestasi $S$. oryzae dan $T$. castaneum tanpa dry ice mengalami penurunan karena tidak adanya pengaruh $\mathrm{CO}_{2}$ yang menyebabkan kelembaban bertambah dan beras juga mulai berkurang dan rusak oleh hama yang memiliki populasi hama paling besar.

Penambahan dan pengurangan berat beras tidak terjadi secara signifikan antar perlakuan karena hanya bertambah atau berkurang beberapa gram saja. Hal tersebut bisa terjadi pula karena memang pengaruh dry ice tidak memberi pengaruh nyata pada berat beras atau adanya kesalahan dalam pengukuran berat beras awal. Pihak produsen beras menimbang beras dengan timbangan manual sedangkan berat beras di akhir ditimbang dengan timbangan digital.

\section{Warna Beras}

Warna beras merupakan salah satu ciri fisik kualitas beras yang dapat dilihat langsung secara visual. Warna beras yang putih bersih umumnya lebih disukai oleh konsumen karena terlihat lebih menarik dan tidak kotor.

Tabel 3. Pengaruh dry ice terhadap warna beras selama lima minggu

\begin{tabular}{llll}
\hline \multirow{2}{*}{ Dosis Dry Ice } & Perlakuan & $\begin{array}{l}\text { Skor } \\
\text { Awal }\end{array}$ & $\begin{array}{l}\text { Skor } \\
\text { Akhir }\end{array}$ \\
\hline \multirow{2}{*}{0 g/beras $5 \mathrm{~kg}$} & $\mathrm{~A}$ & 4 & 3 \\
& $\mathrm{~B}$ & 4 & 3 \\
\hline \multirow{3}{*}{$8 \mathrm{~g} /$ beras $5 \mathrm{~kg}$} & D & 4 & 3 \\
& E & 4 & 3 \\
& $\mathrm{~F}$ & 4 & 3 \\
\hline \multirow{3}{*}{10 g/beras $5 \mathrm{~kg}$} & $\mathrm{C}$ & 4 & 3 \\
& G & 4 & 3 \\
& $\mathrm{H}$ & 4 & 3 \\
\hline
\end{tabular}

Keterangan: Skor $1=$ Putih kusam kekuningan

Skor 2 = Putih kusam

Skor $3=$ Putih

Skor 4 = Putih bening (Utami 2011) .

Pengamatan warna beras ini dilakukan di awal dan di akhir pengamatan untuk membandingkan terjadi atau tidaknya perubahan warna beras setelah diberi perlakuan dan disimpan selama lima minggu. Warna beras setiap varietas beras berbeda-beda. Beras

Efikasi dry ice terhadap sitophilus oryzae dan tribolium castaneum pada beras ................... 
yang dipakai pada penelitian ini merupakan beras $\mathrm{C} 4$ yang sebenarnya hampir sama dengan beras IR64. Menurut Ricky (2011) beras C4 seperti beras IR 64 namun ukurannya lebih pendek serta gemuk dan warnanya juga lebih bening.

Beras penelitian ini setelah diberi dry ice dan disimpan selama satu setengah bulan secara keseluruhan masih tetap sama warnanya hanya berkurang sedikit putihnya yang awalnya putih bening menjadi putih biasa. Adanya perbedaan perlakuan diberi tidaknya dry ice serta perbedaan dosis dry ice tidak berpengaruh nyata pada warna beras.

\section{Bau Beras}

Bau beras merupakan salah satu kualitas beras yang dinilai oleh banyak konsumen. Beras yang apek karena lama disimpan tentu menurunkan minat konsumen untuk membelinya. Pengamatan bau beras juga dilakukan di awal dan di akhir pengamatan untuk membandingkan terjadi atau tidaknya perubahan bau beras setelah diberi perlakuan dan disimpan selama lima minggu.

Pengukuran bau beras ini dilakukan secara skoring untuk menentukan standar pasti tingkat bau beras. Bau beras di awal masih seperti bau beras normal dan setelah diberi berbagai perlakuan serta disimpan selama lima minggu tidak terjadi perubahan bau beras. Hal tersebut menunjukkan bahwa dry ice tidak mempengaruhi bau beras bahkan setelah disimpan selama lima minggu. Aktivitas hama Sitophilus oryzae dan Tribolium castaneum juga tidak membuat bau beras berubah karena beras belum disimpan terlalu lama.

Tabel 4. Pengaruh dry ice terhadap bau beras selama lima minggu

\begin{tabular}{llll}
\hline Dosis Dry lce & Perlakuan & $\begin{array}{l}\text { Skor } \\
\text { awal }\end{array}$ & Skor akhir \\
\hline \multirow{2}{*}{0 g/beras $5 \mathrm{~kg}$} & $\mathrm{~A}$ & 4 & 4 \\
& $\mathrm{~B}$ & 4 & 4 \\
\hline \multirow{2}{*}{8 g/beras $5 \mathrm{~kg}$} & $\mathrm{D}$ & 4 & 4 \\
& $\mathrm{E}$ & 4 & 4 \\
& $\mathrm{~F}$ & 4 & 4 \\
\hline \multirow{3}{*}{10 g/beras 5 kg } & $\mathrm{C}$ & 4 & 4 \\
& $\mathrm{G}$ & 4 & 4 \\
& $\mathrm{H}$ & 4 & 4 \\
\hline
\end{tabular}

Keterangan: Skor $1=$ Bau apek dan menyengat Skor 2= Bau apek dan agak menyengat Skor $3=$ Bau sedikit apek

Skor 4= Bau beras normal (Ardita 2013).

\section{Rasa Nasi}

Beras dengan kualitas yang baik tentu saja juga akan menghasilkan rasa nasi yang enak.

Penentuan rasa nasi dalam penelitian dilakukan di awal dan di akhir pengamatan setelah beras diberi perlakuan dan disimpan selama lima minggu. Standar tingkat rasa nasi dilakukan secara skoring.

Tabel 5. Pengaruh dry ice terhadap rasa nasi selama lima minggu

\begin{tabular}{lllll}
\hline Dosis Dry lce & Perlakuan & Skor Awal & Skor Akhir & Keterangan \\
\hline 0 g/beras $5 \mathrm{~kg}$ & $\mathrm{~A}$ & 4 & $2,5 \mathrm{~b}$ & Enak \\
& $\mathrm{B}$ & 4 & $1,4 \mathrm{a}$ & Tidak enak \\
\hline \multirow{2}{*}{$8 \mathrm{~g} /$ beras $5 \mathrm{~kg}$} & $\mathrm{D}$ & 4 & $1,7 \mathrm{a}$ & Kurang enak \\
& $\mathrm{E}$ & 4 & $1,5 \mathrm{a}$ & Kurang enak \\
& $\mathrm{F}$ & 4 & $3 \mathrm{~b}$ & Enak \\
\hline \multirow{3}{*}{$10 \mathrm{~g} /$ beras $5 \mathrm{~kg}$} & $\mathrm{C}$ & 4 & $1,2 \mathrm{a}$ & Kurang enak \\
& $\mathrm{G}$ & 4 & $3 \mathrm{~b}$ & Enak \\
& $\mathrm{H}$ & 4 & $2,9 \mathrm{~b}$ & Enak \\
& $\mathrm{I}$ & 4 & $3 \mathrm{~b}$ & Enak \\
\hline
\end{tabular}

Keterangan: Angka yang diikuti huruf yang sama menunjukan tidak berbeda nyata pada Uji Jarak Berganda Duncan pada taraf $5 \%$. Skor 1 = Tidak enak, Skor 2 = Kurang enak, Skor $3=$ Enak, Skor $4=$ Enak sekali.

Berdasarkan tabel 5, skor rasa nasi awal sama yaitu enak sekali karena beras masih baru dan belum diberi perlakuan apapun. Skor di akhir pengamatan berbeda-beda karena tingkat rasa dari responden juga berbeda-beda. Rasa nasi dari berkisar 1,2 sampai 3 yang berarti standar rasa dari tidak enak, kurang enak dan enak. Skor terendah 1,2 berasal dari beras perlakuan dengan dosis dry ice $10 \mathrm{~g}$ tanpa $S$. oryzae dan $T$. castaneum, sedangkan skor tertinggi adalah perlakuan $\mathrm{F}$ (infestasi $S$. oryzae dan $T$. castaneum dengan dosis dry ice $8 \mathrm{~g} /$ beras $5 \mathrm{~kg}$ dan pembungkus dry ice tisu keras), G (infestasi $S$. oryzae dan $T$. castaneum dengan dosis dry ice $10 \mathrm{~g} / \mathrm{beras} 5$ $\mathrm{kg}$ dan pembungkus dry ice kain keras), dan I (infestasi S. oryzae dan T. castaneum dengan dosis dry ice $10 \mathrm{~g} / \mathrm{beras} 5 \mathrm{~kg}$ dan pembungkus dry ice tisu keras) dengan skor 3. Perlakuan $\mathrm{G}$ dan I memiliki skor rasa yang tinggi dengan pemberian dosis dry ice 10 $\mathrm{g} /$ beras $5 \mathrm{~kg}$, padahal perlakuan tersebut merupakan perlakuan dengan infestasi $S$. oryzae dan $T$. castaneum yang seharusnya mempengaruhi rasa nasi karena kotoran hama dapat menyebabkan beras bau tidak enak. Sedangkan perlakuan $\mathrm{C}$ yang juga diberi dry ice $10 \mathrm{~g} /$ beras $5 \mathrm{~kg}$ tanpa infestasi $S$. oryzae dan $T$. castaneum memiliki skor rendah dengan kriteria tidak enak. Hal tesebut membuktikan bahwa pemberian dry ice tidak berpengaruh nyata terhadap rasa nasi. Keberadaan hama dan dry ice pada penelitian ini tidak memberikan pengaruh berarti. 


\section{KESIMPULAN DAN SARAN}

\section{Kesimpulan}

Berdasarkan penelitian yang telah dilaksanakan dapat diambil kesimpulan sebagai berikut:

1. Penggunaan dosis dry ice sebesar $10 \mathrm{~g} /$ beras $5 \mathrm{~kg}$ dengan pembungkus dry ice kain keras dan tisu keras lebih efektif dalam mengendalikan Sitophilus oryzae dan Tribolium castaneum dengan nilai mortalitas mencapai 90,83 \%. Penggunaan perlakuan dry ice dengan dosis dan pembungkus yang berbeda tidak berpengaruh terhadap populasi imago dan larva akhir hama.

2. Dry ice tidak memberi dampak terhadap berat beras serta kualitas beras (warna beras, bau beras dan rasa nasi).

\section{Saran}

Berdasarkan penelitian yang telah dilakukan bahwa dry ice dapat dijadikan fumigan dalam skala lapangan. Kerja dry ice dalam penelitian ini dirasa kurang maksimal karena mortalitas tertinggi belum mencapai $100 \%$ karena beberapa faktor yang mempengaruhi. Oleh karena itu perlu adanya penelitian lebih lanjut mengenai penelitian yang sama dengan pengamatan peubah yang lebih baik seperti dosis dry ice, suhu dan kelembaban lingkungan hama, usia hama dan lain-lain. Plastik yang digunakan pada penelitian ini terlalu tipis sehingga terjadi kerusakan mekanis, sehingga ke depannya aplikasi dry ice dalam skala lapangan harus memenuhi syarat fumigasi seperti umumnya yaitu kedap gas oksigen dan kemasan beras yang digunakan harus tebal untuk mengatasi kebocoran fumigan.

\section{DAFTAR PUSTAKA}

Anggara AW, Sudarmaji. 2009. Hama pasca panen padi dan pengendaliannya. Balai Besar Penelitian Tanaman Padi.http://litbang.deptan.go.id. Diakses pada tanggal 21 Mei 2014.

Ardita OR. 2013. Pengaruh penggunaan Dry Ice terhadap Sitophilus oryzae pada beras dalam kemasan plastik. Skripsi. Fakultas Pertanian, Universitas Sebelas Maret Surakarta.

Fadhullah V. 2013. Laporan hama pasca panen Tribolium

castaneum.http://semuatentangpertanian.blogspot. com. Diakses pada tanggal 27 Mei 2014.

Fauziah AR, Noortasiyah, Nor T. 2001. Cara pengujian mutu fisik gabah dan beras. Temu Teknis Fungsional Non Peneliti.

Harpini B. 2013. Standar teknis perlakuan fumigasi ethyl formate. Badan Karantina Pertanian.

Henie. 2012. Es Kering. http://sikluskimia. blogspot. com. Diakses pada tanggal 21 Mei 2014.

Ricky. 2011. Beras C4. http://Pwtasikmalaya. indonetwork.co.id. Diakses pada tgl 30 Maret 2015.

Sakul EH, Jacklin SSM, Dalvian T, Revfly IFG, Sanusi G. 2012. Pengendalian hama kumbang logong (Sitophylus oryzae L.) dengan menggunakan ekstrak biji pangi (Pangium edule Reinw.). Eugenia. 18(3), Desember 2012.

Utami DP. 2011. Analisis pilihan konsumen dalam mengkonsumsi beras organik di kabupaten Sragen. Mediagro. 7(1): 41-58. 